\title{
Trends in the Use of Eye Care Services in Adults Treated for Diabetes between 2008 and 2017 in France: A Nationwide Study
}

\author{
Audrey Cougnard-Grégoire ${ }^{\mathrm{a}}$ Jean-François Korobelnik ${ }^{\mathrm{a}, \mathrm{b}}$ \\ Marie-Noëlle Delyfer ${ }^{a, b}$ Vincent Rigalleau ${ }^{a, c}$ Vincent Daien $^{d-f}$ \\ Catherine Creuzot-Garcher ${ }^{g}{ }^{h}$ Cécile Delcourt ${ }^{a}$ \\ a University of Bordeaux, Inserm, Bordeaux Population Health Research Center, Team LEHA, UMR 1219, \\ Bordeaux, France; ${ }^{b}$ Service d'Ophtalmologie, $\mathrm{CHU}$ de Bordeaux, Bordeaux, France; ' $N u$ trition-Diabetology, $\mathrm{CHU}$

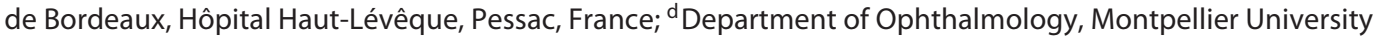 \\ Hospital, Montpellier, France; ${ }^{e}$ University of Montpellier, Montpellier, France; ${ }^{f}$ Inserm, U1061, Montpellier, France; \\ ${ }^{9}$ Department of Ophthalmology, University Hospital Dijon, Dijon, France; ${ }^{\text {h}}$ Eye and Nutrition Research Group, CSGA, \\ UMR 1324 INRA, Dijon, France
}

\section{Keywords \\ Diabetes · Ophthalmology · Eye care use · Epidemiology · Optical coherence tomography $\cdot$ Intravitreal injection}

\begin{abstract}
Purpose: To describe the use of eye care services among adults treated for diabetes from 2008 to 2017 in the French population. Methods: We used a random representative sampling of the French national health insurance database. Participants were adults treated for diabetes. Data regarding visits to ophthalmologists, eye examination procedures, and medical treatments were extracted using reimbursement codes. Cross-sectional analyses of eye care claims were performed each year from 2008 to 2017 . Results: Less than $50 \%$ of people with diabetes underwent an annual eye examination (2008: 44.7\%; 2017: 47.9\%), and less than two-thirds underwent a biennial eye examination (2008-2009: 62.6\%; 2016-2017: 66.4\%). From 2008 to 2017, the yearly use of optical coherence tomography examinations increased steadily and markedly from $2.7 \%$ to $16.2 \%$, while the use of fluorescein and indocyanine green angiographies decreased from
\end{abstract}

$2.4 \%$ to $0.9 \%$. In the same period, the yearly rate of intravitreal injection increased from $0.3 \%$ to $1.5 \%$, and the use of laser photocoagulation decreased progressively from 2008 to 2014 (1.3\% vs. $0.7 \%$ ) but slightly increased from 2015 to 2017 (0.8\% vs. 1.0\%). Conclusions: Strategies to increase compliance with eye care recommendations are needed to improve early detection and management of diabetic eye complications.

() 2020 S. Karger AG, Basel

\section{Introduction}

Diabetic retinopathy (DR) is the ocular manifestation of end-organ damage in diabetes mellitus and the most frequent cause of new cases of blindness among adults aged 20-74 years in industrialized countries [1]. It has been estimated that 93 million people worldwide are affected by DR, and 28 million people have sight-threatening stages of DR [2].

Eye care for people with diabetes has been profoundly modified in recent decades because of major progress in karger@karger.com

www.karger.com/ore

Karger ${ }^{\prime}=$

(C) 2020 S. Karger AG, Basel 


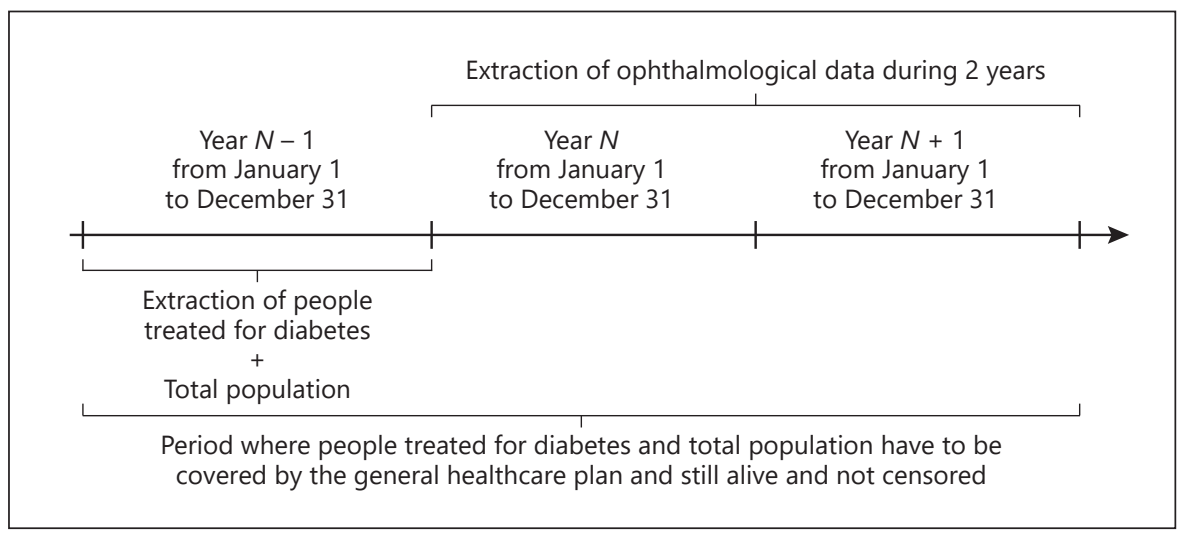

Fig. 1. Design of the study.

retinal imaging and intravitreal therapies. As DR is usually asymptomatic until the late stages when vision loss occurs, annual or biennial routine, dilated, comprehensive eye examinations in diabetic patients are recommended by clinical practice guidelines to detect treatable lesions of the retina, with recommendations varying among countries according to the type, duration, and control of diabetes $[1,3,4]$. Over the past 10 years, significant progress in DR screening was observed, particularly in the United Kingdom [5]. However, the proportions of patients with diabetes who have an annual eye examination vary worldwide from 30 to $70 \%$ [6-8], but no such data are available in France.

The objective of this study was therefore to describe eye care use among French adults treated for diabetes (including ophthalmological visits, imaging procedures, and ophthalmological treatments) and to examine trends in eye care use from 2008 to 2017.

\section{Material and Methods}

\section{Study Design and Data Source}

The French medical-administrative database "Système national d'information inter-régimes de l'assurance maladie" (SNIIRAM) collects data from all individuals affiliated with the health insurance plan in France. It now covers $98.8 \%$ of the French population (approximately 66 million individuals) $[9,10]$. Briefly, this database contains information on all health expenditures: hospital discharge abstracts (with medical diagnoses) and out-of-hospital care (visits, procedures, drugs). From 2007, anonymized beneficiary data were linked over time to allow for longitudinal analyses. The high quality of this database has previously been evaluated and has led to several epidemiological studies, in particular in ophthalmology $[11,12]$.

For the present study, we used the "Echantillon Généraliste des Bénéficiaires" (EGB), which is a random permanent sampling of $1 / 97$ th of the population covered by the SNIIRAM (including from 503,758 individuals in 2008 to 703,261 in 2017). It is based on all ben-

Trends in Eye Care Use in Treated

Diabetes in France eficiaries of the French health insurance system, whether they have received healthcare reimbursements or not. The EGB started in 2004 with data from the CNAMTS (health insurance for salaried workers) and has been progressively enriched over time to include other systems since 2011. For all beneficiaries, the EGB contains sociodemographic data including year of birth, sex, outpatient drug reimbursements with dates of delivery and drug identifiers (pharmaceutical specialty codes and anatomical therapeutic chemical [ATC] classification codes), prescriber's specialization, medical and paramedical visits, medical acts, imaging, and laboratory procedures. The EGB database has previously been described in detail [9, 10, 13-15].

Before 2007, the data were not completely exhaustive. Thus, the present study was restricted to beneficiaries from the CNAMTS from 2007 to 2017 [14].

In accordance with national regulations in place at the time of the study, the protocol was approved by the National Institute of Health and Medical Research (Institut National de la Santé et de la Recherche Médicale, INSERM). There was no further requirement for ethical approval or data protection agency approval because of the anonymized nature of the database. This study was thus exempt from a review by an ethical committee, and written consent was not required. This study conformed to the provisions of the Declaration of Helsinki in 1995 (and revised in Edinburgh 2000).

\section{Total Population}

The total population included individuals 18 years and older, who lived in France in the year $N-1$, and who were still alive and still covered by the CNAMTS until the end of the second period of observation (December 31 of the year $N+1$ ) (Fig. 1).

\section{The Treated Diabetic Population}

The population of treated diabetic individuals in a given year (year $N$ ) was defined as the subjects who received reimbursements for antidiabetic medications or insulin therapy on at least three different dates during the year $N-1$ (Fig. 1). The list of selected drugs corresponded to class A10 of the ATC classification [16], excluding benfluorex (Mediator ${ }^{\circledR}$ ) since benfluorex had many indications outside diabetes. Furthermore, the marketing authorization for benfluorex was withdrawn in France in 2009.

\section{Eye Care of the Diabetic Population}

The eye care data were extracted for a period of 1 year (year $N$ ) and for a period of 2 years (year $N$ and year $N+1$ ) to estimate the 


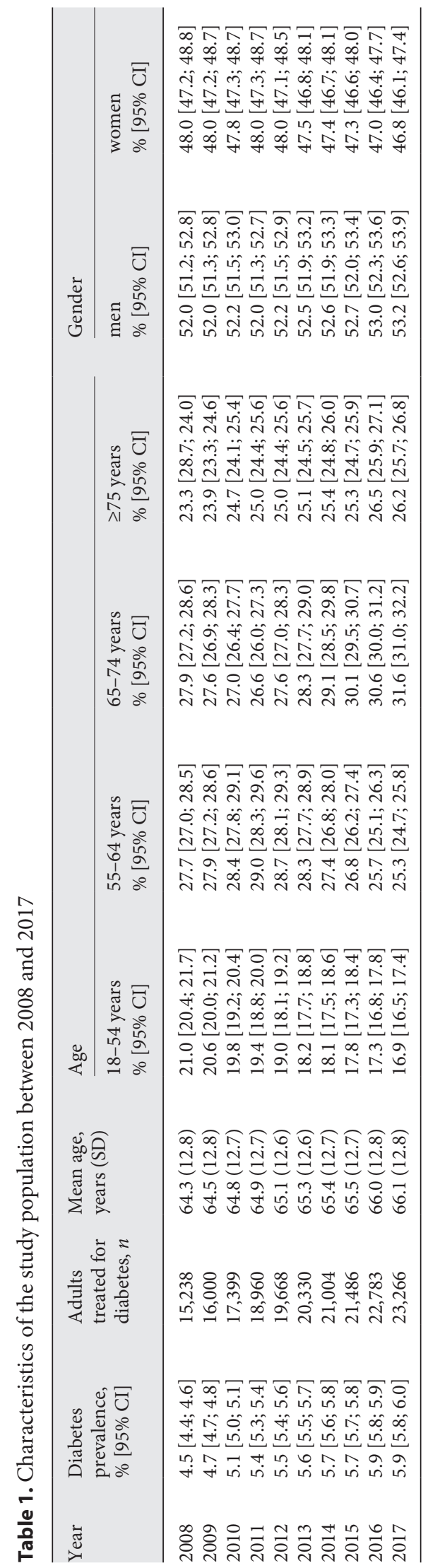

number of annual and biennial eye examinations, respectively (Fig. 1). Data regarding visits to ophthalmologists, retinal imaging procedures, and medical treatments were extracted using the codes for reimbursements and are presented in online supplementary eTable 1 (see www.karger.com/doi/10.1159/000506136 for all online suppl. material). An eye examination was defined as at least one visit to an ophthalmologist or any retinal imaging procedure (fundus ophthalmoscopy, fundus photography, optical coherence tomography [OCT], fluorescein or indocyanine green [ICG] angiography) or other eye and vision examination (e.g., B-scan ultrasonography, optical biometry, gonioscopy, binocular vision, and ocular motricity) during the study period. Indeed, because of the rules for reimbursement, only the most expensive examination may be coded in some cases (for instance, if a visit includes an OCT examination, only the OCT examination will be reimbursed and thus coded). Intravitreal injections (IVIs) included reimbursement for IVIs (codes: BGLB001) and for anti-vascular endothelial growth factor (anti-VEGF) drugs approved for IVI (according to ATC codes: S01LA04 [ranibizumab], S01LA05 [aflibercept]) and corticosteroids (ATC codes: H02AB08 [triamcinolone] and S01BA01 [dexamethasone]). Bevacizumab could not be considered in this study because it is only provided to the hospital for cancer treatment, and off-label intravitreal bevacizumab in DME is extremely marginal in France.

\section{Statistical Analyses}

Repeated cross-sectional studies on use of eye care services (visits, imaging procedures, and treatments) by the diabetic subjects were performed each year from 2008 to 2017 . The results are presented using means \pm standard deviations for continuous variables and $n$ and percentages for noncontinuous variables. All analyses were conducted using SAS Enterprise Guide version 7.1 (SAS Institute Inc., Cary, NC, USA).

\section{Results}

\section{Demographic Characteristics of the Diabetic Study Populations}

In 2008, in France, among the 503,758 individuals included in the EGB, 388,839 were aged 18 years or more. Among those, 338,845 were continuously covered by the general healthcare plan (CNAMTS) and still alive from January 1, 2007 to December 31, 2009. Among those, 15,238 were identified as treated for diabetes, corresponding to a prevalence of treated diabetes of $4.5 \%$ in 2008 (Table 1). The prevalence of treated diabetes increased progressively to $5.9 \%$ in 2017 . In all years, approximately $52 \%$ of diabetic subjects were male. The mean age of the diabetic population in 2008 was 64.3 years and increased continuously to 66.1 years in 2017.

\section{Trends in Eye Examinations}

As shown in Figure 2 and detailed in online supplementary e-Tables 2 and 3, between 2008 and 2016, less 


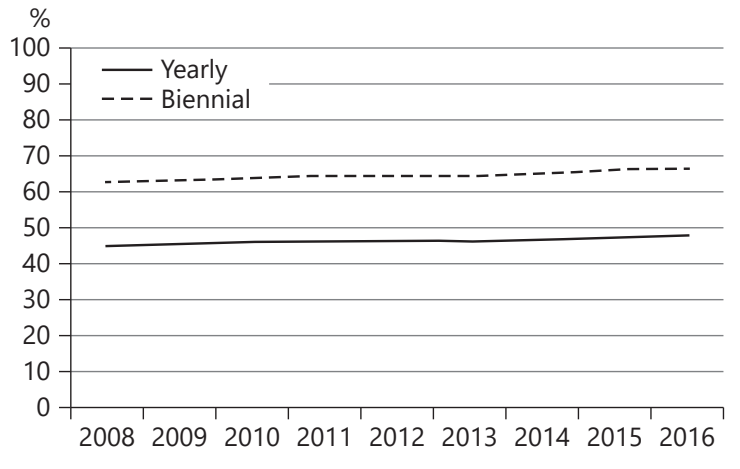

Fig. 2. Rates of yearly and biennial eye examination in adults treated for diabetes (EBG database, 2008-2016).

than half of the individuals treated for diabetes underwent at least one eye examination in the following year, and less than two-thirds underwent at least one ophthalmological visit in the following 2 years. This trend slightly increased between 2008 and 2017, from $44.7 \%$ to $47.9 \%$ for yearly examinations and from $62.6 \%$ to $66.4 \%$ for biennial examinations (online suppl. e-Table 3). As shown in the online supplementary e-Tables 2 and 3, we observed that older patients and women had somewhat better ophthalmological follow-up than younger patients and men, respectively.

As shown in Figure 3 (and detailed in online suppl. eTable 4), the use of OCT examinations increased steadily and markedly, from $2.7 \%$ in 2008 to $16.2 \%$ in 2017 . This increase concerned all age groups. At all time-points, OCT examinations were performed mostly in subjects aged 65 years or more.

Use of fluorescein and ICG angiographies was less frequent and decreased throughout the period (Fig. 3 and online suppl. e-Table 5).

\section{Trends in Treatments}

Figure 4 and online supplementary e-Tables 6 and 7 display the ophthalmological treatments (IVI and laser photocoagulation) performed at least once yearly in the diabetic sample. Between 2008 and 2017, the use of IVI increased five-fold, and this increase was observed in all age groups. Nevertheless, IVI therapy was more frequently used in subjects aged 65-74 and over 75 years than in younger subjects, irrespective of the year (online suppl.

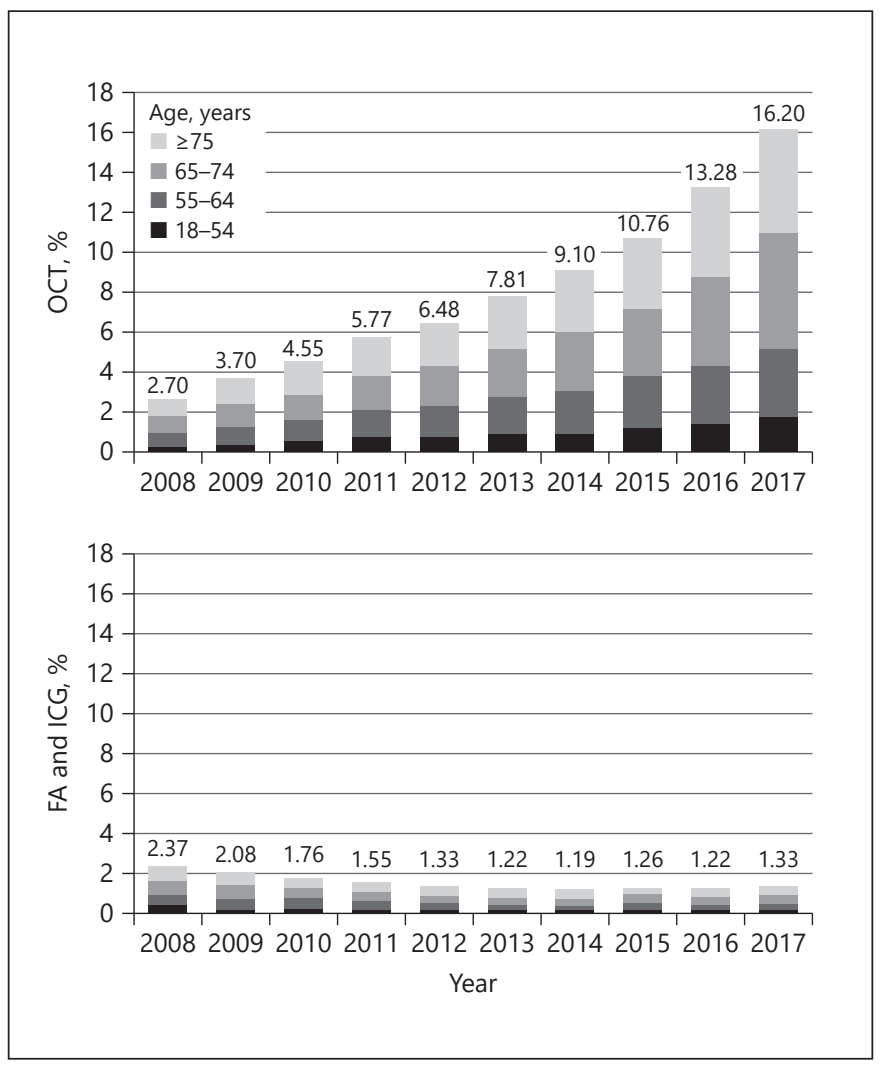

Fig. 3. Yearly rates of examinations with optical coherence tomography (OCT) and fluorescein (FA) and indocyanine green (ICG) angiographies in adults treated for diabetes (EGB database, 20082017). Yearly rate is the percentage of individuals having undergone at least one OCT (or fluorescein and ICG angiographies) examination in the following year.

e-Table 6). IVI therapy was more frequent in women than in men in 2008, but this difference was smaller in 2017. Anti-VEGF and corticosteroids both increased between 2008 and 2017 (data not shown). However, the increase was higher for anti-VEGF than for corticosteroids. In 2008 , the number of subjects with at least one anti-VEGF reimbursement was at least twice the number of subjects with at least one corticosteroid reimbursement during the year $(0.1 \%$ [95\% CI: $0.09 ; 0.2]$ vs. $0.06 \%$ [95\% CI: 0.03 ; 0.1 , respectively). In 2017, prescriptions for at least one anti-VEGF were five-fold more frequent than those for corticosteroids (1.2\% [95\% CI: $1.1 ; 1.3]$ vs. $0.3 \%$ [95\% CI: $0.2 ; 0.4]$, respectively).

Regarding laser photocoagulation (Fig. 4 and online suppl. e-Table 7), we observed a progressive decrease between 2008 and 2014 and a slight increase from 2015 to 2017 , with similar trends in the different age groups for both periods. 

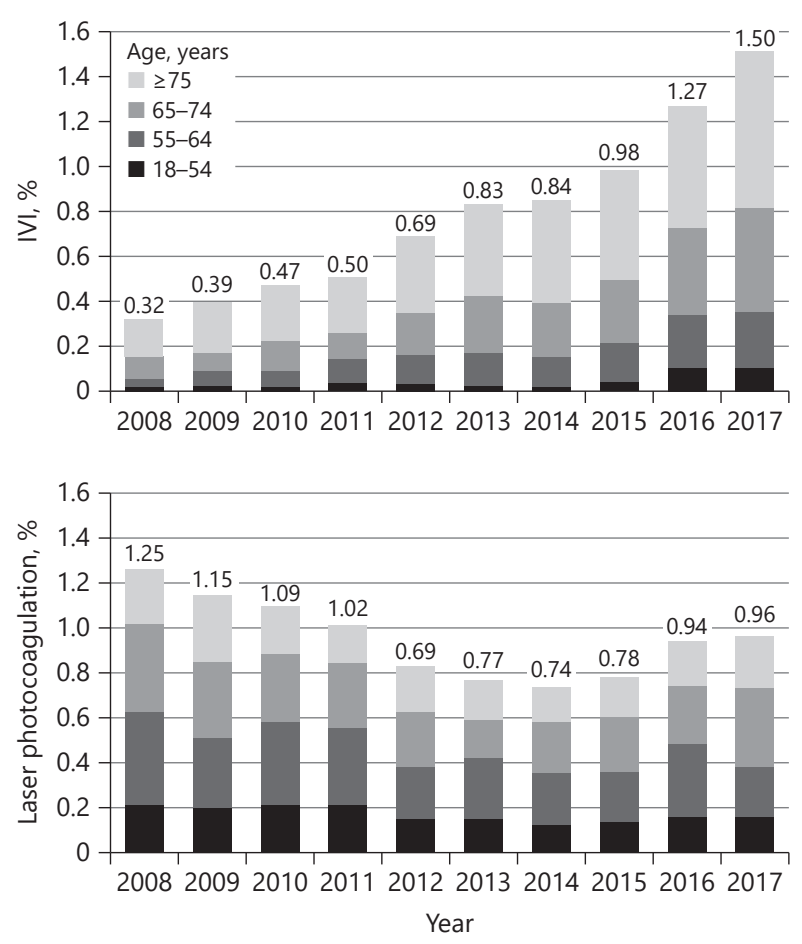

Fig. 4. Yearly rates of treatments with intravitreal injection (IVI) and laser photocoagulation, among adults treated for diabetes (EGB database, 2008-2017). Yearly rate is the percentage of individuals having undergone at least one IVI (or laser) treatment in the following year.

\section{Discussion}

This study describes the use of eye care services of diabetic French adults between 2008 and 2017. During this period, the prevalence of treated diabetes increased from $4.5 \%$ to $5.9 \%$ in the EGB sample. These prevalence rates are very close to estimates from previous French studies with a higher prevalence of treated diabetes in men than in women and with increase in age $[17,18]$.

This study confirms that eye care for treated diabetic patients has undergone major changes in the last decade. Concerning therapies, laser photocoagulation was the gold standard for the treatment of both DME and PDR before the advent of IVI therapies, which were first authorized and covered for this indication in 2012 in France. Indeed, in the present study, the yearly use of IVI continuously increased from $0.32 \%$ to $1.50 \%$ between 2008 and 2017, while laser photocoagulation decreased from $1.25 \%$ in 2008 to $0.74 \%$ in 2014 , but slightly increased again from 2015 to 2017 . The same trend was observed in a Korean study. The proportion of subjects receiving laser treatment among patients with DR decreased continuously from 2006 to 2013 (11.4\% to 6.9\%, respectively) [7]. The higher percentages from the Korean study in comparison with those from our study can be explained by the denominator, which comprised persons with DR in the Korean study and persons with diabetes in our study. We do not have a clear explanation on the increase of laser photocoagulation from 2015 to 2017. This may be related to secondary use of laser photocoagulation in cases treated with IVI therapy or to new imaging modalities (in particular ultra-wide-field fluorescein angiography), allowing more diagnosis of peripheral ischemia.

Yearly use of OCT imaging also increased from $2.8 \%$ to $16.2 \%$ between 2008 and 2017, while use of fluorescein and ICG angiographies slightly decreased from $2.4 \%$ in 2008 to approximately $1.3 \%$ in 2017 . This may be related to the approval of anti-VEGF IVI therapy, because the prescription for it relies on an anatomical evaluation provided by an OCT examination.

Despite these major improvements in eye care for people with diabetes, adherence to recommended eye examination guidelines remained poor throughout the study period. Less than half of the individuals treated for diabetes underwent at least one eye examination in the following year and less than two-thirds in the following 2 years. Our results are in the range of previous studies from industrialized countries, based on self-reported data. For instance, the 2009-2013 retrospective cohort study of Kaiser Permanent Southern California (KPSC) reported that $70 \%$ of subjects were non adherent to the annual examination guidelines [8]. In Europe, in the 1997-2012 repeated cross-sectional study from Germany, the prevalence of annual eye care service utilization was 69\% between 1997 and 2001 and $56.0 \%$ between 2008 and 2012 [6].

Several factors may explain the low adherence of French diabetic patients to the recommendation for regular eye examinations. First, the accessibility of ophthalmological care is often cited as a barrier to adequate eye screening. In France, in contrast with many other countries, all eye examinations, including those for prescriptions for optical correction (i.e., eyeglasses and contact lenses), are performed by ophthalmologists [19]. In 2017, on average, there were 7.5 ophthalmologists per 100,000 inhabitants, with high disparities according to geographical areas ( 0.5 ophthalmologists per 100,000 in Mayotte in the Indian Ocean vs. 23.8 in Paris). A survey on 2,700 French ophthalmologists reported that the mean delay to obtain a visit in 2017 was 80 days [20]. 
Second, implementation of specific DR screening programs has been shown to efficiently increase adherence to screening [21]. For instance, in England, a screening program was implemented by the NHS in 2003 [5, 22]. In 2015-2016, of the 3,083,401 individuals with diabetes in England, the NHS Diabetic Eye Screening Program offered screening to 2,590,082 (the noneligible people were those who were already followed by an ophthalmologist for diabetes-related eye disease). A total of 2,144,007 people with diabetes were actually screened (82.8\%) [5]. In France, a similar screening program was tested in the Paris area beginning in 2004 [23]. It was based on 17 hospitals, 11 primary healthcare centers, and two prisons equipped with nonmydriatic retinal cameras. The photographs were taken by trained nurses or orthoptists and interpreted by 7 ophthalmologists. This program was successful in increasing annual screening rates from 50\% in 2001 (before the implementation of the program) to $72.4 \%$ in 2005 (1 year after the implementation of the program) [24].

Based on this experience, in 2014, a national system of fundus color photography in primary care clinics or hospitals with deferred grading by an ophthalmologist was implemented for people with diabetes without signs of $\mathrm{RD}$ who were younger than 70 years [3]. However, in our study, the proportion of people with diabetes having used this system was low: it began in 2014 with a yearly rate of $0.04 \%$, which increased to $0.15 \%$ in 2017 . Reasons for such a low use of this new system need to be determined and may include the lack of access to retinographs in the primary care setting and ophthalmologists to perform grading.

The use of mobile ophthalmic units may also help to improve early diagnosis of RD in areas with a lack of ophthalmologists (such as rural areas). In Burgundy, over the 2004-2005 period, 676 patients were screened using an itinerant nonmydriatic camera [25]. Among those, 8.6\% had DR and $55 \%$ had not undergone an eye examination within the previous 2 years.

Finally, a lack of adequate eye screening may be linked to personal attitudes and beliefs. For instance, employed younger adults are less likely to adhere to recommendations; this was also observed in the present study (39\% of individuals aged 18-54 years had annual examination versus $48 \%$ of those aged 65 years or more). Diabetic patients also tend to underestimate the importance of ophthalmological examination at regular intervals and the risk of vision loss, even if warned by their physician, because of the asymptomatic nature of most DR cases [2628]. This highlights the need for adequate information and education regarding eye care for diabetic patients, particularly from general practitioners [28].

Trends in Eye Care Use in Treated Diabetes in France
It is clearly necessary in the near future to implement different strategies aimed at increasing adherence to eye care recommendations, including better information and education of diabetic patients regarding eye care and DR, the implementation of RD screening programs combining fundus color photographs taken by professionals other than ophthalmologists (for instance, optometrists or nurses) [23] and the use of mobile ophthalmic units to visit the farthest patients [25]. Moreover, the use of new technologies, such as automated grading software (e.g., IDx-DR software) [29], wide-field fundus imaging, or the use of smartphone-based fundus photography using artificial intelligence [30] may facilitate screening for diabetes-related eye disease.

Our study has strengths and limitations. Its strengths include first the study setting. Data on the use of eye care services were obtained from administrative records, which are an objective and exhaustive source [13] and were not provided by patient self-report, which is in contrast with the majority of previously published studies. Health insurance databases are thus ideal to assess compliance with recommendations at the population level [9, $31,32]$. EGB constitutes a representative random sample of the affiliates of the National Health Insurance System and is one of the world's largest databases. To our knowledge, this is the first study providing information on use of eye care services among French diabetic individuals over a 10 -year period.

Limitations of the present study are mostly related to the inherent characteristics of the database. Because of the availability of data since 2008 , this study was restricted to patients covered by a general plan (salaried workers) and did not include those covered by other specific healthcare plans (which would mainly be representative of civil servants, students, farmers, or self-employed workers). However, the database was representative of more than threequarters of the French population [14]. Moreover, the prevalence rates of diabetes in the present study are similar to previous estimates for French adults [18, 33, 34].

Our sample includes only people whose diabetes is known and treated with medication. Individuals whose diabetes is not known and those whose diabetes is managed only by diet are not included because they cannot be traced in the EGB.

In addition, our study covers all types of diabetes treated pharmacologically (type 1 , type 2 , transient diabetes, such as gestational diabetes, induced diabetes, or other special situations for which cure or remission are possible). Nevertheless, type 2 diabetes accounts for more than 92\% of diabetic patients in France [35]. 
Conversely, the frequencies of eye examinations, IVI, OCT, and fluorescein and ICG angiography might have been slightly underestimated as the healthcare system is authorized to bill for only two services (even if more than two services have been performed), and data on services and drugs dispensed during hospitalization are not available in the database. In addition, Avastin ${ }^{\circledR}$ (bevacizumab) IVI is not available in the database as this drug is delivered only in hospital and is not approved in France for the treatment of DME and thus only very rarely used in this indication.

Regarding laser photocoagulation and IVI therapies, we could not determine the precise indication for these treatments. Some of the diabetic individuals included in this study may have been affected by other macular diseases (neovascular age-related macular degeneration, retinal vein occlusion). Thus, the frequencies of these treatments include treatments for DR and other macular diseases.

In conclusion, although eye care has notably evolved in recent years, with an increasing use of OCT imaging and IVIs, adherence to the recommended regular eye examination schedule remains poor in French people with diabetes and has improved only minimally since 2008 . Strategies to increase compliance with eye care recommendations are needed to improve early detection and appropriate therapeutic management for diabetes-related eye complications.

\section{Statement of Ethics}

Our study is based on the French national medico-administrative database (similar to Medicare). These data are available to researchers through a procedure including approval by the National Institute for Medical Research (INSERM). However, there is no formal submission to an IRB and thus no possibility to obtain a letter from an IRB. Similarly, because these are claims data, no written consent was obtained from the individuals.

\section{Disclosure Statement}

A.C.-G. had travel fees for conferences from Laboratoires Théa. J.-F.K. is a consultant for Allergan, Bayer, Beaver Visitec, Horus, Novartis, KangHong, Roche, Laboratoires Théa, and Zeiss. M.N.D. is a consultant for Allergan, Bayer, Novartis, Bausch \& Lomb, and Laboratoires Théa. V.R. had travel grants for conferences from Bayer, GSK, Novo, Lilly, Pfizer, Takeda, Scherring-Plough, MSD, Novartis, Abbott, Sanofi-Aventis, Lifescann, Merck, AstraZeneca, Biomarin, LucanePharma, Am gen, Nestlé homecare, ASDIA, Pharmadom, Guerbet, Icomed, DinnoSanté, and Gilied science. V.D. is a consultant for Bayer, Novartis, Allergan, Horus, and Laboratoires Théa. C.C.-G. is a consultant for Allergan, Bayer, Horus, Novartis, Bausch \& Lomb, Roche, and Laboratoires Théa. C.D. is a consultant for Allergan, Bausch \& Lomb, Laboratoires Théa, Novartis, and Roche.

\section{Funding Sources}

None.

\section{Author Contributions}

A.C.-G. conceived and designed the study, obtained data, proposed and performed the statistical analyses, contributed to the literature search, drafted the report, and reviewed/edited the manuscript. J.-F.K. conceived and designed the study, provided administrative and technical support, contributed to the literature search, reviewed/edited the manuscript, and revised the report for important intellectual content. M.-N.D., V.R., and C.C.-G. reviewed/edited the manuscript and revised the report for important intellectual content. C.D. conceived and designed the study, provided administrative and technical support, contributed to the literature search, reviewed/edited the manuscript, and revised the report for important intellectual content.

\section{References}

1 American Diabetes Association. 10. Microvascular Complications and Foot Care: Standards of Medical Care in Diabetes-2018. Diabetes Care. 2018 Jan;41 Suppl 1:S105-18

2 Yau JW, Rogers SL, Kawasaki R, Lamoureux EL, Kowalski JW, Bek T, et al.; Meta-Analysis for Eye Disease (META-EYE) Study Group. Global prevalence and major risk factors of diabetic retinopathy. Diabetes Care. 2012 Mar;35(3):556-64.

3 Haute Autorité de santé, HAS. Dépistage de la rétinopathie diabétique par lecture différée de photographies du fond d'œil, 2011. available from: https://www.has-sante.fr/portail/upload/docs/application/pdf/2011-03/fiche de_synthese_retinopathie_vf.pdf

4 Handelsman Y, Mechanick JI, Blonde L, Grunberger G, Bloomgarden ZT, Bray GA, et al. American Association of Clinical Endocrinologists Medical Guidelines for Clinical Practice for developing a diabetes mellitus comprehensive care plan. Endocr Pract. 2011 Mar-Apr;17 Suppl 2:1-53.

5 Scanlon PH. The English National Screening Programme for diabetic retinopathy 2003-2016. Acta Diabetol. 2017 Jun;54(6): 515-25.
6 Baumeister SE, Schomerus G, Andersen RM, Tost F, Markus MR, Völzke H, et al. Trends of barriers to eye care among adults with diagnosed diabetes in Germany, 1997-2012. Nutr Metab Cardiovasc Dis. 2015 Oct;25(10):90615.

7 Song SJ, Han K, Choi KS, Ko SH, Rhee EJ, Park CY, et al.; Task Force Team for Diabetes Fact Sheet of the Korean Diabetes Association. Trends in diabetic retinopathy and related medical practices among type 2 diabetes patients: Results from the National Insurance Service Survey 2006-2013. J Diabetes Investig. 2018 Jan;9(1):173-8. 
8 An J, Niu F, Turpcu A, Rajput Y, Cheetham TC. Adherence to the American Diabetes Association retinal screening guidelines for population with diabetes in the United States. Ophthalmic Epidemiol. 2018 Jun;25(3):25765.

9 Bezin J, Duong M, Lassalle R, Droz C, Pariente $\mathrm{A}$, Blin $\mathrm{P}$, et al. The national healthcare system claims databases in France, SNIIRAM and EGB: powerful tools for pharmacoepidemiology. Pharmacoepidemiol Drug Saf. 2017 Aug;26(8):954-62.

10 Moulis G, Lapeyre-Mestre M, Palmaro A, Pugnet G, Montastruc JL, Sailler L. French health insurance databases: what interest for medical research? Rev Med Interne. 2015 Jun; 36(6):411-7.

11 Creuzot-Garcher C, Benzenine E, Mariet AS, de Lazzer A, Chiquet C, Bron AM, et al. Incidence of Acute Postoperative Endophthalmitis after Cataract Surgery: A Nationwide Study in France from 2005 to 2014. Ophthalmology. 2016 Jul;123(7):1414-20.

12 Daien V, Le Pape A, Heve D, Carriere I, Villain M. Incidence and Characteristics of Cataract Surgery in France from 2009 to 2012: A National Population Study. Ophthalmology. 2015 Aug;122(8):1633-8.

13 Palmaro A, Moulis G, Despas F, Dupouy J, Lapeyre-Mestre M. Overview of drug data within French health insurance databases and implications for pharmacoepidemiological studies. Fundam Clin Pharmacol. 2016 Dec; 30(6):616-24

14 Tuppin P, de Roquefeuil L, Weill A, Ricordeau $\mathrm{P}$, Merlière Y. French national health insurance information system and the permanent beneficiaries sample. Rev Epidemiol Sante Publique. 2010 Aug;58(4): 286-90.

15 Daien V, Korobelnik JF, Delcourt C, Cougnard-Gregoire A, Delyfer MN, Bron AM, et al. French Medical-Administrative Database for Epidemiology and Safety in Ophthalmology (EPISAFE): The EPISAFE Collaboration Program in Cataract Surgery. Ophthalmic Res. 2017;58(2):67-73.

16 WHO, Collaborating Centre for Drug Statistics Methodology, Norwegian Institute of Public Health. The Anatomical Therapeutic Chemical Classification System (ATC) 2018. Available from: https://www.whocc.no/ links/
17 Bonaldi C, Vernay M, Roudier C, Salanave B, Oleko A, Malon A, et al. A first national prevalence estimate of diagnosed and undiagnosed diabetes in France in 18- to 74-year-old individuals: the French Nutrition and Health Survey 2006/2007. Diabet Med. 2011 May; 28(5):583-9.

18 Mandereau-Bruno L, Fosse-Erdoh S. Prevalence du diabète pharmacologiquement traité (tous types) en france en 2015; Disparités territoriales et socio-économiques. Bull Epidemiol Hebd (Paris). 2017;27-28:586-91.

19 Audo I. Current challenges of ophthalmology in France. Arch Ophthalmol. 2010 Oct; 128(10):1358-9.

20 Millien CC, Cavillon M. La moitié des rendezvous sont obtenus en 2 jours chez le généraliste, en 52 jours chez l'ophtalmologiste. Etudes \& Résultats. Direction de la recherche, des études, de l'évaluation et des statistiques. Available from: https://drees.solidaritessante.gouv.fr/IMG/pdf/er1085-2.pdf

21 Pieczynski J, Grzybowski A. Review of diabetic retinopathy screening methods and programmes adopted in different parts of the world. European Ophthalmic Review. 2015; 9(1):49-55.

22 National Health Service. England, United Kingdom. Diabetic eye screening: commission and provide. 2015. Available from: https:// www.gov.uk/government/publications/diabetic-eye-screening-2015-to-2016-data

23 Schulze-Döbold C, Erginay A, Robert N, Chabouis A, Massin P. Ophdiat $\left({ }^{\circledR}\right)$ : five-year experience of a telemedical screening programme for diabetic retinopathy in Paris and the surrounding area. Diabetes Metab. 2012 Nov;38(5):450-7.

24 Pérès K, Matharan F, Daien V, Nael V, Edjolo A, Bourdel-Marchasson I, et al. Visual Loss and Subsequent Activity Limitations in the Elderly: The French Three-City Cohort. Am J Public Health. 2017 Apr;107(4):564-9.

25 Beynat J, Charles A, Astruc K, Metral P, Chirpaz L, Bron AM, et al. Screening for diabetic retinopathy in a rural French population with a mobile non-mydriatic camera. Diabetes Metab. 2009 Feb;35(1):49-56.

26 Sheppler CR, Lambert WE, Gardiner SK, Becker TM, Mansberger SL. Predicting adherence to diabetic eye examinations: development of the compliance withAnnual Diabetic Eye Exams Survey. Ophthalmology. 2014 Jun;121(6):1212-9.

27 Hartnett ME, Key IJ, Loyacano NM, Horswell RL, Desalvo KB. Perceived barriers to diabetic eye care: qualitative study of patients and physicians. Arch Ophthalmol. 2005 Mar; 123(3):387-91.
28 Cavan D, Makaroff LE, da Rocha Fernandes J, Karuranga S, Sylvanowicz M, Conlon J, et al. Global perspectives on the provision of diabetic retinopathy screening and treatment: survey of health care professionals in 41 countries. Diabetes Res Clin Pract. 2018 Sep;143: 170-8.

29 U.S. Food and Drug Administration. FDA permits marketing of artificial intelligencebased device to detect certain diabetes-related eye problems. Silver Spring, MD 209932018 (updated 04/12/2018). Available from: https://www.fda.gov/NewsEvents/Newsroom/PressAnnouncements/ucm604357. htm

30 Rajalakshmi R, Subashini R, Anjana RM, Mohan V. Automated diabetic retinopathy detection in smartphone-based fundus photography using artificial intelligence. Eye (Lond). 2018 Jun;32(6):1138-44.

31 Bezin J, Pariente A, Lassalle R, DureauPournin C, Abouelfath A, Robinson P, et al. Use of the recommended drug combination for secondary prevention after a first occurrence of acute coronary syndrome in France. Eur J Clin Pharmacol. 2014 Apr;70(4):42936.

32 Daien V, Le Pape A, Heve D, Villain M, Bremond Gignac D; Collaborators of the Epidemiology and Safety Program (EPISAFE). Incidence and Characteristics of Congenital Cataract Surgery in France from 2010 to 2012: the EPISAFE Program. Ophthalmic Res. 2017;58(2):114-6.

33 Mandereau-Bruno L, Denis P, Fagot-Campagna AF, Fosse-Edorh S. Prévalence du diabète traité pharmacologiquement et disparités territoriales en France en 2012. Bull Epidemiol Hebd (Paris). 2014;30-31:493-9.

34 Santé Publique France. Prévalence et incidence du diabète. Available from: http://invs. santepubliquefrance.fr/Dossiers-thematiques/Maladies-chroniques-et-traumatismes/Diabete/Donnees-epidemiologiques/ Prevalence-et-incidence-du-diabete

35 Druet C, Roudier C, Romon I, Assogba F, Bourdel-Marchasson I, Eschwege E, et al. Échantillon national témoin représentatif des personnes diabétiques, Entred 2007-2010. Saint-Maurice Institut de veille sanitaire. Available from: http://opac.invs.sante.fr/ doc_num.php?explnum_id=8600
Trends in Eye Care Use in Treated Diabetes in France
Ophthalmic Res 2020;63:452-459

DOI: $10.1159 / 000506136$ 